\title{
O CICLO DA PRODUÇÃO DE INTELIGÊNCIA COMO APOIO À ESTRATÉGIA DE TOMADA DE DECISÃO ORGANIZACIONAL
}

\section{THE CYCLE OF INTELLINGENCE PRODUCTION AS SUPPORT ORGANIZACIONAL DECISION MAKING}

\author{
Ismael Cristofer Baierle* E-mail: ismaelb@via.com.br \\ Rejane Frozza* E-mail: frozza@unisc.br \\ Elpídio Oscar Benitez Nara* E-mail: elpidio@unisc.br \\ Liane Mahlmann Kipper* E-mail: liane@unisc.br \\ Universidade de Santa Cruz do Sul, UNISC, Santa Cruz, RS
}

\begin{abstract}
Resumo: Muitos autores afirmam que para enfrentar mudanças aceleradas no ambiente produtivo e social e, principalmente, para responder com agilidade às demandas dos clientes e/ou usuários de uma organização, são necessárias informações e seu gerenciamento. Processos de tomada de decisão ainda levam em conta apenas experiências passadas, sendo que este modelo não atende mais aos preceitos do mundo corporativo atual, visto a velocidade com que o mercado e a concorrência estão na busca de aperfeiçoamento. Centrado nos conceitos de Inteligência Competitiva e Inteligência Artificial, este artigo tem como objetivo mostrar a importância do tratamento das informações, focando os processos de tomadas de decisões, e apresentar um modelo para sua organização e armazenamento. As conclusões apontam para a utilização de sistemas inteligentes, contribuindo na melhoria do processo de tomada de decisão e objetivando obter respostas com alto padrão de qualidade referente às demandas do mercado.
\end{abstract}

Palavras-chave: Inteligência Competitiva. Inteligência Artificial. Informações. Sistemas Inteligentes. Tomada de Decisões.

Abstract: Many authors claim that to cope with rapid changes in social and productive environments, and especially for responding quickly to customer demands and / or users in an organization, information is needed and its management. Decision-making processes also take into account only the past experiences, and this model no longer meets the precepts of today's corporate world, considering the speed with which the market and competition are in search of improvement. Centered on the concepts of Competitive Intelligence and Artificial Intelligence, this article aims to show the importance of information processing, focusing on the processes of decision making and provide a model for their organization and storage. The findings point to the use of intelligent systems, contributing to improved decision-making process and seeking to obtain answers with high quality standards relating to market demand.

Keywords: Competitive Inteligence, Artificial Intelligence, Intelligence and Intelligent Systems, Decision Making.

\section{INTRODUÇÃO}

No atual cenário mundial, é difícil para as empresas obterem vantagens competitivas sustentáveis apenas com a rápida alocação de novas tecnologias e 
com a excelência da gestão eficaz de recursos financeiros, pois segundo Kaplan e Norton (1997), "As empresas estão a caminho de uma transformação revolucionária.

A competição da era industrial está se transformando na competição da era da informação. As empresas bem sucedidas sempre eram aquelas que incorporavam as novas tecnologias aos ativos físicos que permitiam a produção em massa eficiente de produtos personalizados...". Atualmente, não basta às empresas apenas apresentarem maior produtividade do que seus concorrentes ou conseguir atender a sua demanda, elas devem sim ser muito flexíveis para reagir com rapidez às mudanças competitivas e de mercado.

A vantagem competitiva deve ser encarada como uma situação temporária, estando sempre na busca de informações úteis que alicercem todas as tomadas de decisão. Neste contexto, cada vez mais irão se destacar as empresas que souberem criar um fluxo de informações gerenciais intermitentes e que possam ser usadas como base para toda e qualquer tomada de decisão da empresa. Assim, em meio a um mercado de muitas incertezas e estando as organizações empresariais sempre iminentes a passar turbulências, através da TI (Tecnologia da Informação) estas podem ser prevenidas ou diminuídas drasticamente, quando identificadas com antecedência (WANG, 2009). Este artigo propõe que as empresas que têm maior competência na gestão de informação e que souberem criar estratégias que venham ao encontro das necessidades da empresa e dos clientes terão maiores condições de atuação. Para isto é necessária a criação de um método de tratamento de dados dentro da empresa, utilizando princípios de inteligência competitiva, com o auxílio de sistemas baseados em conhecimento. O artigo está organizado da seguinte maneira: a seção 2 aborda um referencial teórico sobre os temas envolvidos na pesquisa; na seção 3 apresentam-se os métodos utilizados; a seção 4 descreve a proposta da pesquisa; as seções 5 e 6 apresentam o sistema proposto e desenvolvido e as seções 7 e 8 as considerações finais. 


\section{ABORDAGEM TEÓRICA}

Esta seção apresenta uma breve fundamentação de alguns temas relevantes para a pesquisa, como a gestão da informação, inteligência competitiva e suas etapas, relação entre inteligência artificial e gestão do conhecimento.

\subsection{Gestão da informação}

$\mathrm{Na}$ atualidade, com a sociedade interligada e interagindo em tempo real, a informação é a principal arma das empresas para sua sobrevivência (STAREC; GOMES; BEZERRA, 2005). Para os usuários de informação mais bem-sucedidos, aperfeiçoamentos contínuos no gerenciamento da informação fazem com que seja praticamente impossível para os concorrentes acompanhá-los, além de acreditar que mapear o fluxo de informação numa organização precisa ser encarado como estratégia competitiva, tendo em vista a relevância da informação nos dias atuais (PRUSAK; MCGEE, 1994). Toda e qualquer decisão envolve riscos, já que decisões são tomadas por pessoas, e pessoas são falíveis. Em muitas organizações, decisões ainda são tomadas por tomadores de decisão que confiam basicamente em seus instintos, no bom senso e na própria experiência profissional. Mas, no cenário atual, este modelo de tomada de decisões não atende mais às necessidades de um mundo corporativo com o volume crescente de dados e com a obrigatoriedade de se obter informações relevantes e prioritárias de forma instantânea. Desta forma, a identificação da estratégia competitiva deve ser capaz de predizer o cenário futuro, levar em conta o pensamento do negócio e planos de emergência para responder aos desafios futuros e incertos do mercado (WU; LIN, 2009). Mas ainda há barreiras como a complexidade dos domínios de aplicação do conhecimento e a incerteza da manutenção no futuro (KOH; HÁ; KIM; LEE, 2005).

Muitos gestores deparam-se diariamente com uma enxurrada de dados, mas conseguem filtrar pouca coisa para transformá-los em informação relevante e prioritária para a tomada de decisões mais complexas. Como consequência, decisões importantes são tomadas sem as informações necessárias, isto é, sem uma correta análise dos dados. 
Assim, estarão no controle dos eventos aqueles que tiverem a capacidade de antecipar o poder da tecnologia da informação. As empresas que não conseguirem responder prontamente a este desafio, ficarão na iminência de ter que se adaptar às mudanças impostas pelas demais, fazendo com que elas fiquem em desvantagem competitiva (PORTER, 2000). Para que se possa ter um gerenciamento eficaz e focado em resultados, é necessário munir-se de muita informação, acompanhando tendências de mercado e concorrentes, uma vez que essas informações devem ser usadas na formulação de estratégias e tomada de decisões dentro da organização. Segundo Robbins (2000, p. 83), umas das ferramentas mais usadas para isso, e que está em amplo desenvolvimento no mundo inteiro, é a inteligência competitiva.

\subsection{Inteligência competitiva}

Nos últimos anos a inteligência competitiva (IC) tornou-se importante na gestão estratégica das empresas. O objetivo central é combinar, desenvolver e apresentar um plano que ajude a atingir uma vantagem competitiva para a organização (BOSE, 2008; KHALIFA et al., 2008). Surge como um instrumento estratégico para aumentar a competitividade das empresas (PELSMACKER et al., 2005). Seu princípio básico é buscar informações básicas sobre o mercado em geral e sobre concorrentes. Informações precisas sobre os movimentos e tendências do mercado e da concorrência, podem possibilitar antecipar as ações dos concorrentes em lugar de somente reagir a elas. Acrescenta-se ainda que a IC não é espionagem industrial, e estima-se que $90 \%$ de todas as informações que uma empresa precisa para a tomada de decisões críticas e compreender seus concorrentes já é público ou pode ser sistematicamente desenvolvido a partir de dados públicos (TEO; CHOO, 2001). Robbins (2000, p.83) ainda continua: "Informação específica sobre o setor em que você atua e sobre seus concorrentes encontram-se cada vez mais disponíveis nos bancos de dados eletrônicos. Muitas empresas chegam a comprar regularmente os produtos dos concorrentes e pedem a seus engenheiros que os desmontem para descobrir inovações técnicas adicionais". Anúncios, promoções, comunicados à imprensa, relatórios encaminhados ao governo, relatórios anuais, ofertas de emprego em classificados, reportagens e estudos setoriais são exemplos de fontes 
de informações prontamente disponíveis às organizações. Atualmente, a internet é uma ferramenta de grande valia também, mas nem todas as empresas tratam esta ferramenta de forma ideal e que possa ser importante num processo de tomada de decisão (VAUGHAN; YOU, 2008). Na busca de sintonia com as grandes transformações, as empresas precisam trabalhar com informações que agreguem alto valor ao processo de tomada de decisão e à criação de novos conhecimentos, promovendo, continuamente e de forma sustentável, vantagens competitivas sobre seus concorrentes prioritários, quer pela maior eficiência em seus processos administrativos, produtivos e de distribuição, maior margem de manobra na fixação de preços competitivos, quer pela maior capacidade de diferenciação, mediante à criação de poder superior de mercado (SENAI, 2005).

\subsection{Etapas para desenvolvimento de plano de inteligência competitiva}

O processo de desenvolvimento de um plano de Inteligência Competitiva, baseado na adaptação do ciclo de produção da inteligência proposto por Starec, Gomes e Bezerra (2005), pode ser resumido em cinco etapas: Planejamento, Coleta, Análise, Disseminação e Desenvolvimento do Plano (tomada de decisão).

$\mathrm{Na}$ etapa de planejamento, é preciso se estabelecer um foco e identificar quais são as necessidades de informação. Após a decisão sobre o foco da informação, passa-se para a $2^{a}$ fase, que é a coleta de dados. Todos os dados que forem levantados nesta etapa serão considerados inteligência bruta e precisam ser trabalhados para que possam ser utilizados na formulação das estratégias e tomada de decisões. De acordo com Cervo (2002, p. 45) "Há diversas formas de coletas de dados, todas com suas vantagens e desvantagens. Na decisão do uso de uma forma ou de outra o pesquisador levará em conta a que menos desvantagens oferecer, respeitando os objetivos da pesquisa". Ainda neste raciocínio, Rudio (1997) explica que a coleta de dados é a fase de uma pesquisa cujo escopo é obter informações da realidade, sendo que podem existir diversos meios e instrumentos para obtenção dessas informações, dependendo do objetivo e do foco que se tem para a pesquisa. Também se faz necessária a obtenção de informações de 
concorrentes, através de coleta de campo e de dados publicados nos meios de comunicação mencionados anteriormente.

$\mathrm{Na}$ terceira etapa, é necessário fazer uma análise de todos os dados coletados, para que eles possam ser transformados em inteligência. Para Diehl e Tatim (2004), a análise consiste em atribuir valor a alguma coisa, sendo necessário definir o ponto de vista pelo qual ela será feita, para que se chegue ao resultado esperado, sendo nesta etapa que a utilização de técnicas de análise dos sistemas baseados em conhecimento irá contribuir para a transformação de dados em informações úteis. É um dos pontos mais críticos para a implantação da IC, já que requer que o analista conte com habilidades específicas e que conheça muito bem o assunto pesquisado. Mesmo que o processo seja automatizado, somente o raciocínio humano será capaz de avaliar a relevância e a credibilidade das informações. Nessa etapa, torna-se muito importante que se tenha um foco bem definido, para que não sejam analisados dados que parecem ser importantes, mas que não tem relação com o real objetivo. O propósito desta análise é que possam ser oferecidas alternativas para a tomada de decisões e de ações, e não de apenas aprender sobre os competidores.

A quarta etapa é de disseminação das informações, ou seja, da geração do conhecimento. Nesta etapa, os dados analisados, já transformados em informação são entregues aos tomadores de decisão. Para Starec, Gomes e Bezerra (2005, p. 178), “A transmissão da informação se dá por meio verbal ou formal...". É importante que essas informações sejam distribuídas e fiquem disponíveis para todos os níveis e/ou setores da organização. A disseminação pode se realizar por meio de um software de gestão do conhecimento, que irá fornecer informação específica para a tomada de decisão. Com a disseminação, é possível realizar um acompanhamento das informações geradas e como elas podem contribuir para que se volte à primeira etapa do processo de inteligência competitiva, que é o planejamento e identificação de necessidades.

A quinta etapa é a avaliação de todo o processo de inteligência, etapa que foi incluída no plano de inteligência competitiva. Deve-se avaliar se o plano de inteligência criado foi eficiente, sob o ponto de vista das informações criadas, ou seja, se ele foi importante para o estrategista ou tomador de decisões da empresa. 
Na figura 1, é ilustrado todo o processo de desenvolvimento de um plano sistemático de inteligência competitiva, ressaltando que após a coleta, análise e disseminação, os dados são transformados em inteligência, ou seja, informações passíveis de serem usadas numa posterior tomada de decisão. Após essa tomada de decisão, o próprio resultado já leva a um novo planejamento e para uma nova pesquisa e levantamento de novos dados, tornando bem claro que o sistema de inteligência competitiva nunca deve ter fim para que seja eficaz dentro da organização.

Figura 1 - Ciclo da Produção de Inteligência e Inteligência Artificial

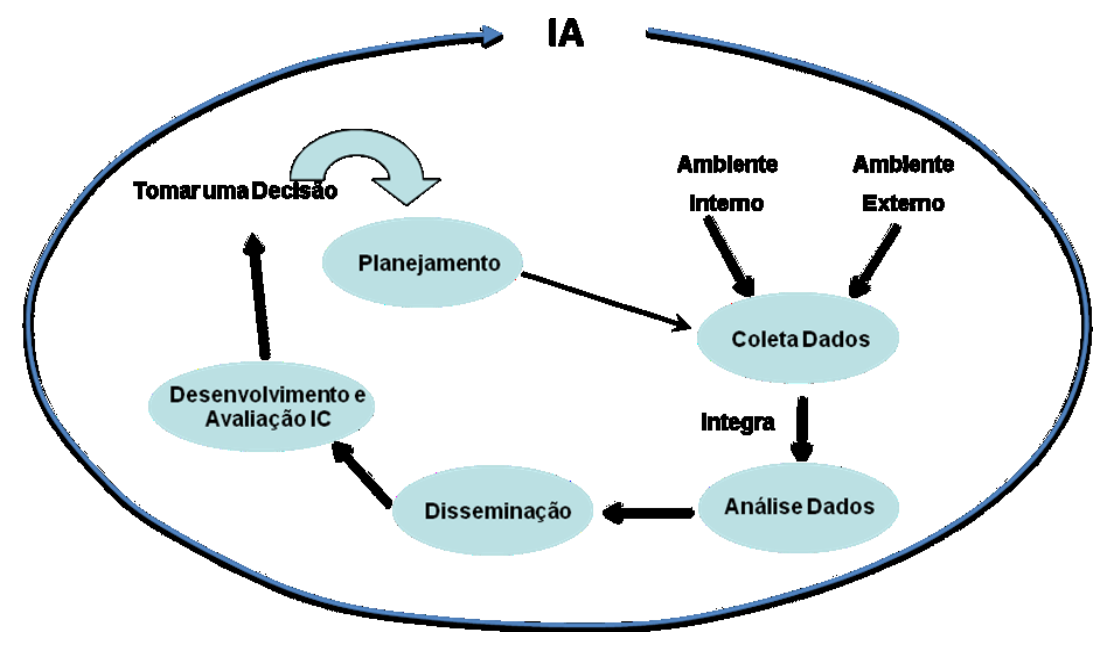

Fonte: Adaptado de Starec; Gomes; Bezzerra, (2005)

Essas avaliações são imprescindíveis tanto para o constante desenvolvimento e aprimoramento do plano, bem como para a própria sobrevivência dele, uma vez que o plano de IC só se consolida como uma inteligência quando seus resultados são utilizados para a tomada de decisões. Se o processo terminar na quarta etapa, a empresa terá adquirido apenas informações, uma vez que a inteligência só existe quando estas informações são utilizadas para a definição de estratégias para tomada de decisão. É importante também que se verifique constante e frequentemente se o produto da IC foi ou está sendo disseminado de acordo com as necessidades reais de informação da empresa. Isso se pode conseguir através de pesquisas com os usuários do produto da inteligência, em reuniões internas com a equipe de IC, a fim de que se analise e melhore cada etapa do sistema. Outra forma muito importante para avaliação do plano, é que se tenha um banco de indicadores que mostrem os resultados obtidos pela empresa através de decisões tomadas com 
base no plano de IC, tais como aumento de vendas, produtividade, participação de mercado, entre outros. Para que se tenha um controle eficaz do processo e se consiga dinamizar o fluxo de informações dentro da organização, é necessária a utilização de sistemas inteligentes, através de software de manipulação e armazenamento de dados e conhecimento. Esses sistemas inteligentes, subárea da Inteligência Artificial(IA), estão presentes em todas as etapas do processo da produção de inteligência, conforme mostra a figura 1, uma vez que entre as habilidades inteligentes está a habilidade de coleta, armazenamento e recuperação eficiente de grande quantidade de informação, para resolver problemas ou tomar decisões (REZENDE, 2003).

\subsection{Inteligência artificial e gestão do conhecimento}

Os primeiros conceitos de inteligência artificial (IA) surgiram em 1956, nos Estados Unidos, na Darthmouth College, hoje Carnegie Mellon Univertsity (CMU). Considerando-se os primitivos computadores da época e poucas ferramentas de programação, poucos acreditavam que um computador poderia realizar alguma atividade dita então inteligente (RUSSEL; NORVIG, 2004). Sistema é um conjunto de elementos ou componentes que interagem para atingir objetivos, tendo entradas, mecanismos de processamento, saídas e feedback (BEAL, 2004). Um sistema é denominado inteligente porque utiliza software capaz de manipular conhecimento e informação de forma inteligente. Estes softwares são desenvolvidos especificamente para serem usados em problemas que requerem conhecimento e especialização humana. A definição preferida depende da pessoa, e sobretudo, dos seus interesses e objetivos. No contexto deste trabalho, IA é o resultado da aplicação de técnicas e recursos, especialmente de natureza não numérica, viabilizando a solução de problemas que exigiriam do humano certo grau de raciocínio e de perícia. A solução destes problemas com recursos tipicamente numéricos é muito difícil. Por isso é que a IA caracteriza uma nova era da computação, a era do processamento não numérico (REZENDE, 2003, p.21). O mesmo autor acrescenta ainda que, além de dinamizar o fluxo de trabalho da empresa, os sistemas inteligentes também 
asseguram a preservação e padronização dos processos de decisão envolvidos no negócio, refletindo-se assim na otimização dos seus processos industriais.

A representação do conhecimento é uma forma de modelagem do conhecimento humano para o conhecimento armazenado em uma máquina, para que exista compreensão da situação existente, a fim de construir um sistema de apoio à decisão (WERMUTH; FROZZA; PAZOS, 2007). Somente será considerado um sistema de Inteligência Artificial (IA) se os processos de aquisição, triagem, de ordenação e de interpretação da informação forem contínuos, ou seja, constantemente dados devem chegar e alimentar o sistema de IA (REZENDE, 2003, p. 52). Nos últimos anos, a tecnologia de informação dentro das empresas, nesse caso a IA, é vista como fator de viabilização da competição em abrangência mundial, bem como de criação de novas estratégias de negócios, de novas estruturas organizacionais e de novas formas de relacionamento entre empresas e entre empresas e seus consumidores (SANTOS; LAURINDO, 2004). As empresas estão observando que o conhecimento está se tornando o mais valioso recurso estratégico para ser competitivo na nova economia (WU; LIN, 2009).

O objetivo principal dos sistemas inteligentes é capacitar o computador, por meio de um software, a executar funções realizadas por seres humanos com conhecimento e raciocínio. Em razão disso, o desenvolvimento de tecnologias que privilegiam o conhecimento começam a aparecer cada vez de forma mais acentuada. Estamos entrando na chamada era do conhecimento, que dá início a uma nova abordagem de gestão de pessoas, a Gestão do Conhecimento, pois cada indivíduo é o único capaz de armazenar conhecimento, se este conhecimento for proveniente da interação do homem com o ambiente (QUEL, 2006). Um sistema inteligente que seja eficaz deve ter algumas propriedades específicas, como: processar tarefas como monitoramento, capacidade de coordenar conhecimentos de diferentes fontes, manter a base de dados como gestão do processo de conhecimento e capacidade de se adaptar a um ambiente de mudança (URAIKUL; CHAN; TONTIWACHWUTHIKUL, 2007). No mundo empresarial, dados e informações trafegam dentro das organizações com muita rapidez e de forma bastante elevada, mas muitos desses dados acabam sendo inutilizados, pois não são transformados em conhecimento. É neste ponto que entra a gestão do 
conhecimento. Para que esta ocorra, ambas as partes são de suma importância, ou seja, a gestão deve ser compartilhada entre empregados e empregadores, tendo cada um consciência de sua importância e suas limitações no cenário em que se encontra. Ambos devem trabalhar em sintonia, pois gestão do conhecimento não visa reduzir custos com demissão de funcionários ou maximizar produção com conhecimentos captados da concorrência pelos trabalhadores, mas sim a completa interação entre todos dentro da organização.

Desta forma, a gestão do conhecimento é entendida por muitos como uma arte, ou seja, a arte de criar valor a bens intangíveis de uma organização, gerenciando todo o seu capital intelectual. Na gestão do conhecimento, são traçadas as metas/objetivos pelo tomador de decisões: são realizadas a coleta de dados, sua análise e transformação da informação para o conhecimento. A partir disso, o conhecimento é aplicado em um contexto/domínio para auxílio aos processos de tomada de decisão, a fim de atingir resultados satisfatórios nos negócios da empresa. Em uma sociedade cada vez voltada para o conhecimento, o "trabalhador do conhecimento" será o maior ativo. Este trabalhador será o executivo do conhecimento que sabe alocar o conhecimento para o uso produtivo, assim como o capitalista sabia como alocar o capital para uso produtivo (NONAKA; TAKEUCHI, 1997). Inteligência Competitiva e Inteligência Artificial têm uma ligação direta, pois a IC tem como escopo a enxurrada de dados dentro da organização, isto é, dados devem chegar à empresa de forma intermitente. Já para fazer o tratamento e cruzamento de todos esses dados, utiliza-se a IA, que já terá um foco previamente definido e vai fazer com que todos esses dados se transformem em informações passíveis de serem usadas na tomada de decisões.

\section{MÉTODO CIENTÍFICO}

Para o desenvolvimento desta pesquisa, utilizou-se uma abordagem quantiqualitativa. Todos os dados levantados e que são usados no modelo representacional são quantitativos. De acordo com Richardson (1999, p. 39) as pesquisas qualitativas "podem descrever a complexidade de determinado problema, analisar a interação de certas variáveis, compreender e classificar processos 
dinâmicos...". Desta forma, neste trabalho, a experiência do gestor são os dados qualitativos.

Portanto, esta pesquisa se enquadra, segundo os meios, como um estudo de caso, pois foi realizada a partir de dados reais de uma empresa fabricante de acessórios para motociclistas. Como um método de pesquisa, o estudo de caso parece ser apropriado para investigação de fenômenos quando não existem leis básicas para determinar quais fatores e relacionamentos são importantes (FIDEL, 1992). Ele objetiva a descoberta, ou seja, o investigador se mantém atento a novos elementos que poderão surgir, buscando novas respostas e novas indagações no desenvolvimento do seu trabalho.

O trabalho de campo exige, além de muita observação por parte do pesquisador do cenário organizacional, instrumentos de coleta de dados adequados à situação em estudo. Foram utilizadas ferramentas como a internet, através de pesquisas em sites como IBGE, Detran e Abraciclo, visita a clientes potenciais, informações repassadas por representantes e análise das cartas-resposta enviadas pelos clientes, sendo que muitas informações relevantes foram obtidas também através de notícias de jornais, revistas e televisão. Com os dados disponíveis, passou-se para o desenvolvimento do ciclo da produção de inteligência dentro da organização e entendimento da cadeia de valor do conhecimento.

\section{PROPOSTA DO SISTEMA INTELIGENTE ORGANIZACIONAL}

A estrutura desta seção discute de que maneira os dados levantados poderão contribuir para a tomada de decisão, e principalmente, qual o papel desempenhado pela Inteligência Competitiva e Inteligência Artificial. Apresenta-se um breve histórico da empresa estudada, a importância do levantamento de dados e o porquê de serem apenas estudados e avaliados os dados do setor de marketing.

\subsection{Descrição do ambiente pesquisado}

O estudo de caso foi realizado no setor de marketing de uma empresa do ramo de acessórios para motociclistas, atuante no mercado nacional, que possui 
uma alta sazonalidade de vendas, devido a diversos fatores, explicitados na figura 2. Atuante no ramo de acessórios para motociclistas, tendo foco na proteção do usuário contra as intempéries do tempo (chuva), sua grande ameaça é devida ao fato de os concorrentes estarem a mais tempo neste ramo, tendo assim marca já consolidada pelos usuários, dificultando muitas vezes a penetração dos produtos em novos mercados. Para que se consiga penetrar em novos mercados, é preciso, primeiramente conhecê-lo muito bem, a fim de inserir produtos que serão absorvidos pelos usuários. Para isso, as informações mais relevantes e que influenciam diretamente na venda dos produtos, são as informações mercadológicas, ou seja, dados que são coletados e disponibilizados pelo setor de marketing da empresa.

Todo o levantamento de dados, avaliação do seu grau de importância e quais seriam as pessoas envolvidas nesse processo, foram realizados através de reuniões informais com a direção da empresa. O gestor da empresa, de acordo com seu conhecimento tácito adquirido ao longo dos anos, foi de fundamental importância quando da seleção dos dados com maior grau de relevância, ou seja, que influenciam diretamente quando da necessidade de tomada de alguma decisão. A empresa em questão já possuía um grande número de dados históricos, que vão desde dados internos (como o histórico de venda) até dados externos (como o número de emplacamentos), mas tem um grande problema, que é transformar esses dados em informação passível de ser utilizada em uma posterior tomada de decisão.

A tomada de decisão está na base estratégica da empresa, sendo que esta sempre vai ao encontro da missão e visão da empresa, que tem sempre o intuito de atender e surpreender as expectativas dos clientes, não esquecendo da valorização das pessoas como parte integrante de uma sociedade em transformação. A ética nos negócios, satisfação dos clientes, primar por inovar sempre, apoiar o crescimento do indivíduo (clientes) e preservar os bons hábitos e costumes são as políticas de trabalho da empresa e as principais premissas para que sejam tomadas decisões estratégicas, visando atender ao máximo esses requisitos, tornando a empresa competitiva e com uma posição pró-ativa frente às mudanças do cenário competitivo. A problemática é como fazer com que essas informações se tornem úteis e confiáveis, razão pela qual se propôs um sistema que faça esse trabalho, 
facilitando a tomada de decisão aos gestores, conforme será descrito na seção seguinte.

\section{SISTEMA BASEADO EM CONHECIMENTO PARA APOIO À TOMADA DE DECISÃO ORGANIZACIONAL}

Para que se possa tomar uma decisão fundamentada em situações anteriores de sucesso ou de insucesso, é preciso que estas situações estejam de alguma forma, estruturadas e armazenadas. Uma tomada de decisão não empírica e sim baseada em fatos reais, pode auxiliar na melhoria dos processos e atividades desenvolvidas em qualquer área de conhecimento. Como no cenário desta pesquisa há uma base de informações já existentes do mercado nacional de motocicletas e acessórios, conhecidas pelo setor de marketing, mas que não se consegue por vezes recuperá-las e torná-las uma ferramenta de ajuda para ações estratégicas. Os sistemas baseados em conhecimento auxiliam exatamente no processo de modelagem, armazenamento, recuperação e disseminação do conhecimento, transformando dados em informações, chegando ao nível de conhecimento.

$\mathrm{Na}$ figura 2, está representado o modelo proposto e desenvolvido, onde se visualiza o funcionamento do processo de geração de conhecimento. As informações mercadológicas levantadas na empresa constituem as entradas para o sistema e também são os fatores que influenciam as ações estratégicas. As informações são então processadas pelo sistema, que resultará em ações a serem realizadas, refletindo um processo de tomada de decisão, consolidando assim o processo de IC. As entradas são analisadas a partir de um conjunto de regras préestabelecido pelo tomador de decisão da empresa. Esse conjunto de regras é acionado pelo motor de inferência, que faz com o sistema realize uma busca inteligente para chegar a uma decisão. A decisão e todo processo de uso das informações constituem o bem mais precioso para o gestor, fazendo com que este tenha em mãos um bem intangível, mas que proporcionará um ganho à organização se bem aplicado. 
Figura 2 - Sistema de Planejamento do Conhecimento

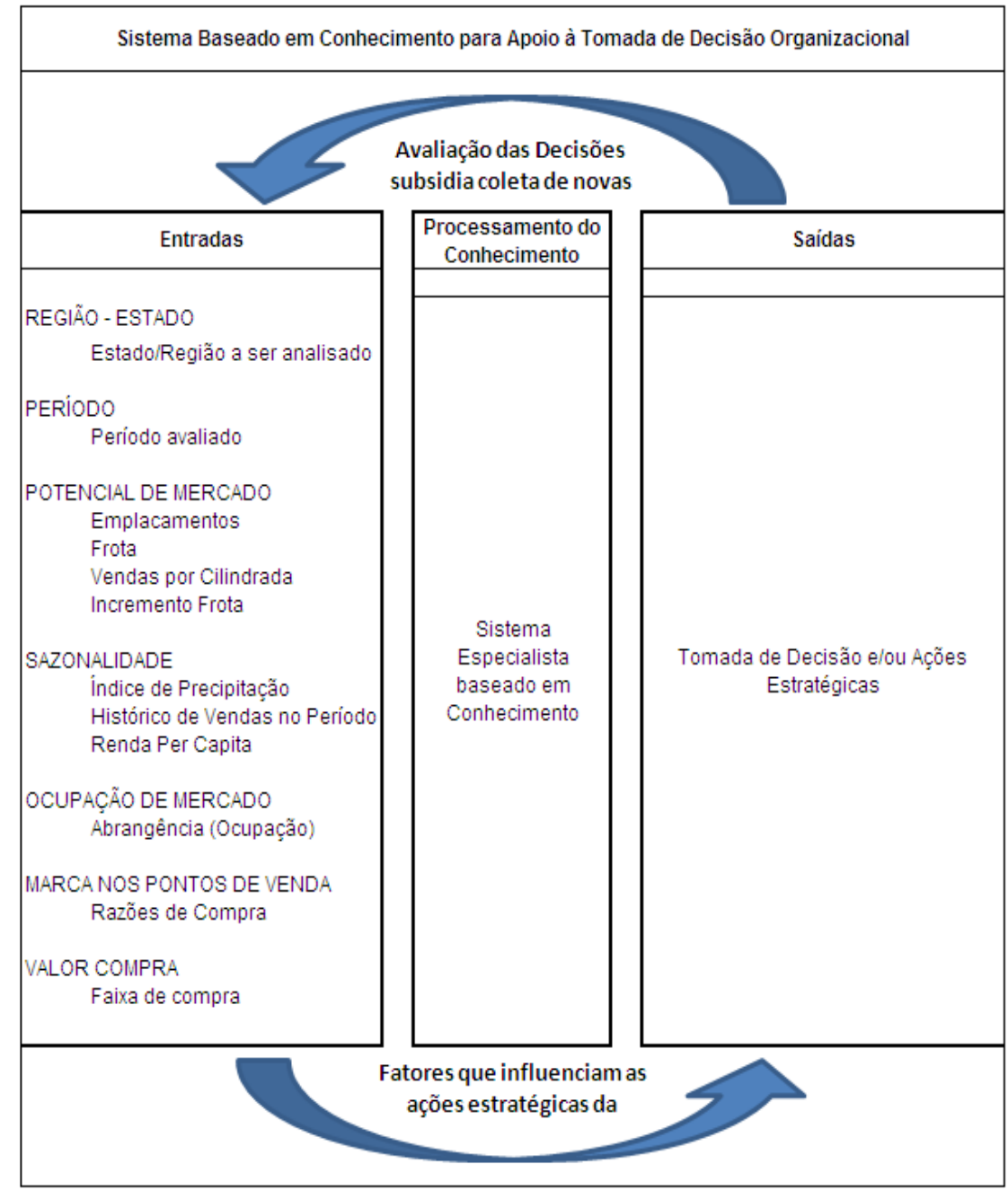

Fonte: Adaptado de Gaither e Frazier (2001)

Os autores Gaither e Frazier (2001) propuseram um sistema de planejamento das necessidades de recursos, ou seja, um sistema que com ajuda de um MRP (Planejamento de Necessidade de Materiais), MPS (Programa Mestre de Produção) e CRP (Planejamento das Necessidades de Capacidade) fazem o planejamento automático de recursos. Possui entradas de dados funcionais, como previsão da demanda, e como saída possui o programa de produção. Na adaptação a esta pesquisa, há vários dados de entrada que irão alimentar a fase de tratamento dos dados, através do sistema baseado em conhecimento, cuja saída refere-se a tomada de decisão. Na figura 2, estão principais dados do setor de marketing da empresa analisada. Estado/região e período influenciam diretamente, pois há estados com mais venda de motos que outros, por exemplo, assim como há períodos em que há mais chuva que outros e que então alavancam as vendas.

Revista Produção Online. Florianópolis, SC, v.11, n. 4, p. 1086-1113, out./dez. 2011. 
Outros dados como renda e razões de compra de motos, por exemplo, traçam um perfil de consumidores, e que reflete diretamente na venda dos produtos. Desta forma, foi feito o levantamento de quais seriam os atributos utilizados no sistema, ou seja, aqueles dados a partir dos quais foi possível traçar um perfil dos consumidores, situação do mercado e avaliação do clima de certa região, fatores determinantes para a empresa. Na próxima seção, os atributos utilizados são explicados, bem como as regras que analisam e conduzem a busca por uma solução.

\subsection{Fluxograma do Sistema}

Para melhor entendimento de quais os atributos envolvidos e quais as suas influências para a geração de indicadores de acompanhamento que levarão ao apoio à tomada de decisões, os processos de análise e levantamento de dados foram organizados em sete atividades. A figura 3 mostra como são organizadas essas atividades e quais os atributos envolvidos em cada uma.

Figura 3 - Fluxograma de Atributos do Sistema Especialista.



Fonte: Elaborada pelos Autores 
As atividades são: Planejamento, Levantamento de Dados, Entrada de Dados, Análise Parcial dos Resultados, Análise dos Resultados Parciais, Análise Final dos Dados e Decisão. Estas foram ainda organizadas em cinco grandes processos, de modo a facilitar o seu gerenciamento. Esses cinco processos são Planejamento, Iniciação, Execução, Controle e Encerramento dos Processos. Tal divisão faz parte de um conjunto de práticas para gerenciamento de projetos, chamado de Project Management Body of Knowledge - PMBOK, desenvolvido em 1987 pelo Project Management Institute - PMI, cujo um dos objetivos é a maior facilidade para a gerência de projetos, fazendo com que o processamento das informações seja feito de forma clara e lógica (VARGAS, 2007). Cada um desses cinco processos possui internamente outras atividades, que vão desde a entrada de dados até o seu processamento pelo sistema baseado em conhecimento (sistema especialista).

\subsubsection{Planejamento dos Processos}

Este processo contempla as atividades iniciais do sistema, que são o Planejamento feito pelo gestor e/ou tomador de decisão, que define qual a região que será analisada e em qual período serão buscados os dados históricos, sempre visando à última etapa, que é o apoio à decisão; e o Levantamento de Dados necessários para a próxima atividade, que é a entrada de dados. Esses dados levam em conta os dados históricos, considerando os atributos REGIÃO/ESTADO e PERÍODO (período de tempo que se deseja analisar).

\subsubsection{Iniciação}

Marca o início do processamento de dados. O sistema é alimentado com todos os dados necessários para o processamento nas atividades seguintes. 


\subsubsection{Entrada de Dados}

Os atributos, que foram definidos para o desenvolvimento do sistema baseado em conhecimento e que influenciam diretamente na venda e na promoção da marca, são: EMPLACAMENTO (percentual de emplacamento de motocicletas no período analisado), FROTA (cada estado possui sua participação na frota total de motocicletas do país), INCREMENTO DE FROTA (de acordo com a divulgação constante de números pela ABRACICLO, sabe-se qual foi o incremento da frota), QUANTIDADE DE CHUVA (a quantidade de chuva sofre variações e influenciam diretamente na venda dos produtos), MOTORIZAÇÃO DOMINANTE (índices de venda de motocicletas divididos de acordo com a sua motorização, em cilindradas (CC)), RAZÕES DE COMPRA DE MOTO (pode ser tanto para uso diário como apenas para lazer nos finais de semana), FAIXA DE RENDA DA POPULAÇÃO (mostra qual a faixa de renda da população no estado ou região), PERCENTUAL DE VENDAS NO PERÍODO (dados históricos da empresa), FAIXA COMPRA (valores obtidos através de dados históricos da empresa) e ABRAGÊNCIA DA MARCA (percentual obtido através de pesquisas do setor de vendas/marketing da empresa).

Com a entrada desses dados no sistema especialista, passa-se então para a $1^{\mathrm{a}}$ análise de dados, que através de um conjunto de regras, reúne todos os dados considerados de uma mesma área e os transforma em novos valores, que unidos a outros dados servirão de base para regras mais avançadas na próxima etapa.

\subsubsection{Execução}

Processo em que ocorre a aplicação das regras pré-estabelecidas nos dados fornecidos, ocorrendo, então, as primeiras análises.

\subsubsection{Análise Parcial dos Dados}

Esta é a atividade em que é feita a primeira grande análise dos dados imputados anteriormente, obtendo-se os seguintes dados: POTENCIAL DE MERCADO (indica se o potencial de vendas no estado é baixo, médio, ou alto); 
ÍNDICE DE PRECIPITAÇÃO (diz se o período analisado é um período chuvoso, período de estiagem ou se possui apenas chuvas isoladas); VENDAS POR CILINDRADA (indica qual a motorização mais vendida no estado e em determinado período); RAZÕES DE COMPRA (mostra qual o principal motivo pelo qual a população está adquirindo motocicletas); RENDA PER CAPITA (determina a classe social dominante na região de acordo com dados estatísticos); HISTÓRICO DE VENDAS (indica quanto o estado representa no total das vendas no período) e FAIXA MÉDIA DE COMPRAS (indica qual o valor médio de compras).

\subsubsection{Análise dos Resultados Parciais}

Esta atividade já possui resultados parciais advindos da análise de um conjunto de atributos anteriores. Como é uma análise de resultados parciais, há apenas dois atributos nessa fase, que são PÚBLICO-ALVO (originado do cruzamento dos dados de Razões de Compra e Renda Per Capita da população); e HISTÓRICO COMERCIAL (consiste na união de dados históricos da empresa, de vendas e do valor médio dessas vendas). Como são dados de vendas e disponíveis na empresa, os dois foram cruzados dando origem a mais um atributo. Tanto público alvo como o histórico comercial irão gerar o atributo Oportunidade de Vendas, que fará parte da análise final dos dados e servirá como base para a tomada de decisão.

\subsubsection{Controle}

Realiza o controle dos processamentos anteriores, ou seja, é possível visualizar quais informações se originaram dos dados inseridos nas primeiras etapas, e fazer o controle dos atributos um a um.

\subsubsection{Análise Final dos Dados}

Última atividade antes do final do processo, engloba três atributos considerados muito importantes, que são: OCUPAÇÃO DE MERCADO (valor, em percentual, que representa qual a fatia de mercado que a empresa tem em relação 
aos seus concorrentes); POTENCIAL DE ABSORÇÃO (potencial de mercado, índice de precipitação e vendas por cilindrada são os atributos que indicarão qual o potencial que o estado possui de absorver os produtos em determinado período, servindo como base para o gestor decidir se volta esforços para essa região mesmo sabendo que não irá ter retorno, por exemplo); e OPORTUNIDADE DE VENDAS (oriunda da análise parcial de público alvo e histórico comercial, indicará qual a probabilidade de se fazer uma venda no estado em determinado período, cabendo ao gestor decidir se vale algum esforço ou investimento em força de vendas). Todas as atividades de levantamento e análise de dados encerram-se neste momento.

\subsubsection{Encerramento}

Como o nome já diz, o último processo faz o fechamento de todo o sistema, pois nele que ocorrerá a decisão em si, a última etapa do sistema especialista.

\subsubsection{Decisão}

O gestor irá se munir da informação gerada pelo sistema, que irá o ajudar a tomar a decisão, de acordo com seu planejamento inicial. Por se tratar da última etapa, pode-se visualizar também um relatório com todas as inferências (atributos e regras) geradas pelo sistema até a decisão, para que o gestor possa analisar o resultado atingido pelo sistema especialista. Como saída neste processo, apresentase a decisão, conforme figura 3, com o fim do processamento dos dados, onde as informações geradas devem levar a alguma ação estratégica, e esta deve estar de acordo com o posicionamento da empresa frente ao mercado e suas variações.

\section{MODELO REPRESENTACIONAL E SISTEMA INTELIGENTE DESENVOLVIDO}

Todas as etapas entre a entrada de dados e o encerramento do processo são executadas por um conjunto de regras, que estão armazenadas na base do sistema especialista. Para um tratamento correto de todos os dados do sistema, foi criado um método representacional composto por 144 regras, sendo estas regras aplicadas 
em todos os cinco processos descritos na seção 5.1. Para desenvolvimento do sistema especialista foi utilizado o software Expert SINTA 1995-1997, versão 1.1b, software livre, baseado em conhecimento, criado pelo Grupo SINTA (Sistemas Inteligentes Aplicados), do Laboratório de Inteligência Artificial (LIA) da Universidade Federal do Ceará-UFC. O objetivo do Expert SINTA é simplificar ao máximo as etapas de criação de um Sistema Especialista completo. Para tanto, já oferece uma máquina de inferência básica, fundamentada no encadeamento para trás (LIA, 1999).

Para acompanhamento do conhecimento que é gerado pelo sistema, foram identificados quatro atributos para serem usados como indicadores de acompanhamento, que são os fatores que influenciam diretamente na venda do produto, prospecção de mercado e trabalho da marca. Esses indicadores são: Potencial de Absorção; Público Alvo; Ocupação de Mercado e Oportunidade de Vendas. Para facilitar o entendimento do porque desses quatro indicadores serem os fundamentais para a tomada de decisão, pode-se observar o exemplo do indicador Oportunidade de Vendas, como essas informações são disponibilizadas ao tomador de decisão dentro do sistema, qual a sua influência e algumas das regras que fazem com que se chegue a um resultado que possa servir de base para análise.

Oportunidades de Vendas é o maior conjunto de regras do sistema e serve para fazer o fechamento geral do sistema, uma vez que faz o cruzamento de Público Alvo com Histórico Comercial. Propõe a ação final que deve ser tomada, como se pode observar na figura 4. 


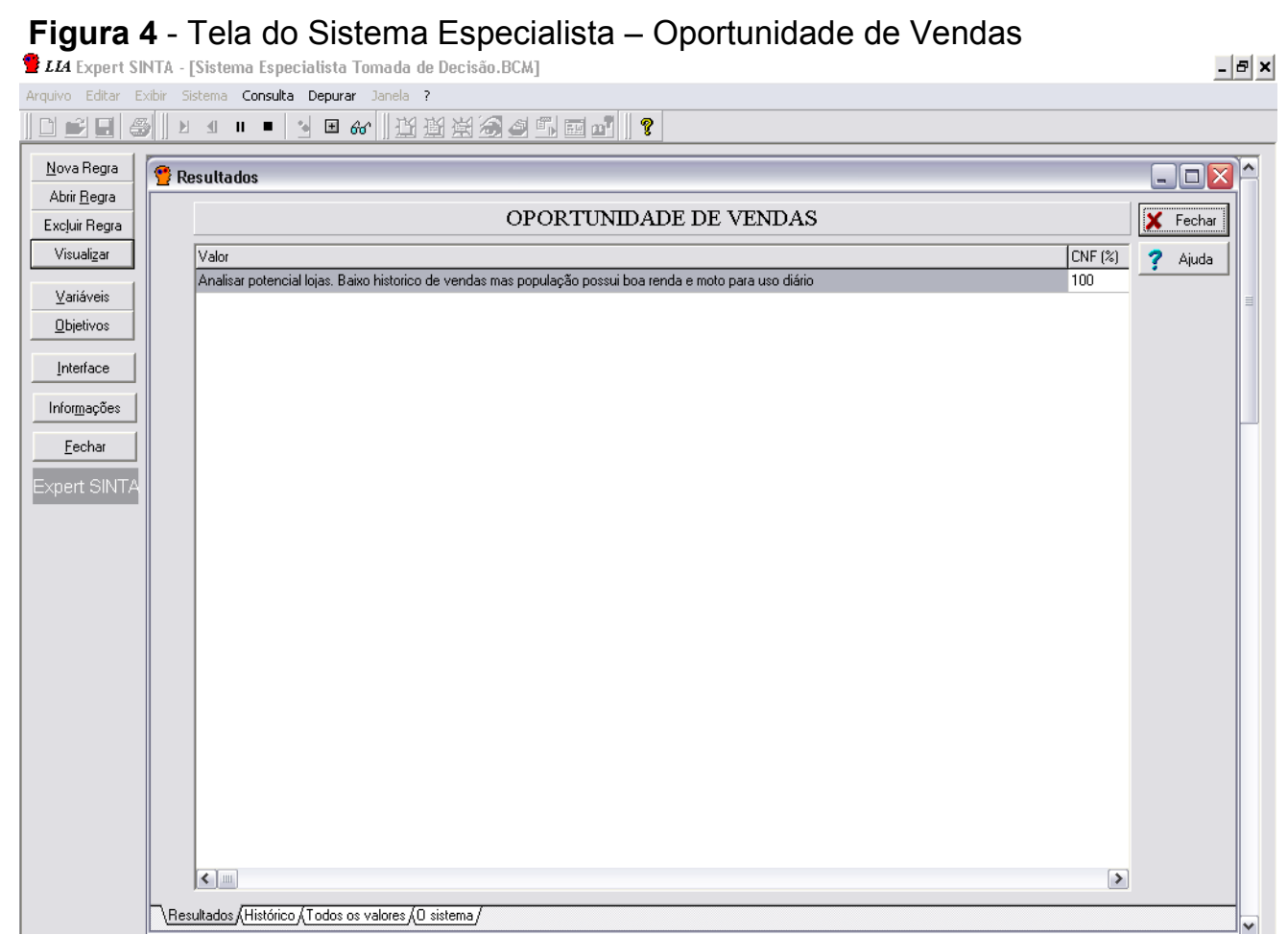

Fonte: Elaborada pelos Autores

Um exemplo de regra que dá origem a este resultado está evidenciada a seguir, sendo que um conjunto bem maior de regras define a oportunidade de vendas, com qualquer mudança no cenário.

Regra 118

SE PÚBLICO ALVO = Grande potencial - Uso diário e boa renda

E HISTÓRICO DE COMERCIALIZAÇÃO = Baixo histórico de vendas

ENTÃO OPORTUNIDADE DE VENDAS = Analisar potencial lojas. Baixo histórico de vendas, mas população possui boa renda e moto para uso diário.

Os possíveis valores deste atributo, determinados pelo sistema especialista, são:

- Analisar potencial das lojas. Baixo histórico de vendas e população possui baixa renda.

- Grande potencial de vendas. Clientes com ótimo potencial. População tem boa renda e utiliza moto para lazer. Investir em produtos com valor agregado.

- Grande potencial de vendas. Clientes compram grandes quantidades. População tem baixa renda, procuram custo mais baixo.

- Grande potencial de vendas. Clientes compram grandes quantidades. População tem boa renda. Investir em produtos com valor agregado.

- Histórico de vendas baixo. Trabalhar mais a marca com produtos de maior valor agregado.

Revista Produção Online. Florianópolis, SC, v.11, n. 4, p. 1086-1113, out./dez. 2011. 
- Oportunidade boa de vendas. População possui boa renda e usam moto eventualmente, mas faixa de compra de clientes está baixa.

- Oportunidade muito boa de vendas. População possui boa renda e usam moto diariamente.

- População com boa renda e utilizam moto para lazer. Avaliar pontos de venda.

- Analisar potencial das lojas. Baixo histórico de vendas, mas população possui boa renda e moto para uso diário.

- Grande potencial de vendas. Clientes com ótimo potencial. População tem boa renda. Investir em produtos com valor agregado.

- Grande potencial de vendas. Clientes compram grandes quantidades. População tem boa renda e utiliza moto para lazer. É possível investir em produtos com valor agregado.

- Histórico de vendas baixo, mas região tem boa renda e maioria utiliza moto para lazer.

- Oportunidade boa de vendas. Faixa de renda Média, mas utilizam moto eventualmente. Investir em produtos com valor agregado.

- Oportunidade boa de vendas. Região de baixa renda. Investir em produtos de baixo custo.

- Oportunidade muito boa de vendas. População possui boa renda e usam moto diariamente, mas faixa compra de clientes está baixa.

- Histórico de Vendas baixo. Trabalhar mais a marca com produtos de baixo custo. Baixa renda da população.

O resultado sobre oportunidade de vendas indicará ao tomador de decisão qual o rumo que ele deverá tomar para que a empresa tenha sucesso frente aos concorrentes e frente às adversidades do mercado. No caso exemplificado, o sistema especialista indicou para o gestor "Analisar potencial das lojas. Baixo histórico de vendas, mas população possui boa renda e moto para uso diário". Com isso, conclui-se que a empresa historicamente vende poucos produtos nessa região no período analisado, conforme dados históricos, sendo que a população local possui uma boa renda e necessita da motocicleta para uso diário, necessitando assim se proteger de frio e chuva, por exemplo. 
O sistema indica então analisar o potencial das lojas, a fim de que se saiba o porquê de o produto não estar sendo vendido na região, que tem grande potencial. Dados como abrangência da marca ajudam aqui, para se saber se a marca está bem divulgada, e o potencial de absorção indica se o período é chuvoso ou não, sendo passível ou não de algum investimento nesse período.

\section{DISCUSSÃO DOS RESULTADOS}

Todos os atributos necessariamente possuem regras para que dados possam ser transformados em informações. Essas regras são pré-estabelecidas de acordo com conhecimentos de mercado, principalmente por parte dos gestores e vendedores da empresa, que estão em contato direto com mercado, clientes e consumidores finais. O sistema entra nesse cenário para ajudar, com esse conjunto de regras, a filtrar de maneira muito mais fácil todos os dados, o que antes dificilmente era feito, principalmente devido à grande quantidade de dados e a dificuldade de reunir todos em um único lugar e fazer com que os mesmos servissem de base para apoio a alguma decisão. Esse processo de reunir dados e transformá-los em informações, através de regras, por exemplo, chama-se de gestão do conhecimento.

No sistema baseado em conhecimento desenvolvido neste trabalho, há um módulo de processamento do conhecimento (motor de inferência), com o uso da técnica de Sistemas Especialistas. Já no sistema de planejamento proposto por (GAITHER; FRAZIER, 2001) havia apenas um planejamento e projeto do processo, escolhendo tipo de processo, estudos do processo/produto, escolha de equipamentos, entre outros, sendo que não desenvolveram um sistema computacional de apoio à tomada de decisões e que facilita escolhas.

O clico de inteligência deve sempre seguir a visão e a missão da empresa, que está no mercado com intuito de atender e surpreender as expectativas dos clientes, nunca se esquecendo da valorização da sabedoria das pessoas como parte integrante da empresa em uma sociedade em transformação, uma vez que a sabedoria é desenvolvida através da vivência e experiência. 


\section{CONCLUSÃO}

Com este trabalho, evidenciou-se que informações são muito importantes em toda e qualquer tomada de decisão, pois somente elas é que dão embasamento e uma referência que garante ao gestor e/ou tomador de decisão chegar a uma decisão adequada frente ao posicionamento da organização no mercado. A Inteligência Artificial entra como suporte nas etapas da inteligência competitiva, garantindo a organização e o armazenamento dessas informações, deixando-as disponíveis para todos os níveis da organização e, principalmente, facilitando o seu acesso quando necessário e para qualquer fim, mas, especialmente, servindo de base para traçar novas estratégias de tomada de decisões.

Observou-se também que o ciclo da produção de inteligência é contínuo, ou seja, tem início, meio, mas não tem fim. Após o planejamento, coleta, análise e disseminação de dados, acrescentaram-se as etapas de desenvolvimento (para posterior tomada de decisão) e avaliação do processo de IC (se foi útil para a tomada de decisão), etapa essa que contribuirá para o planejamento de uma próxima coleta de dados. E para o auxílio em todas as etapas, os sistemas inteligentes auxiliam no tratamento e armazenamento das informações coletadas e geradas após o processo de IC. Desta forma, foram identificados indicadores de acompanhamento, que são os fatores que levam ao posicionamento estratégico e à tomada de decisão.

Após levantados e disponibilizados os dados, realizou-se a sua formalização, através de um método representacional, que é o conjunto de regras, e desenvolveuse um sistema inteligente baseado em conhecimento, a fim de que os dados recebessem o correto tratamento e que servissem de base para ações futuras do gestor da empresa. O sistema influencia diretamente nas decisões da empresa, visto que através dele é possível prever como poderá ser o cenário, através de regras pré-estabelecidas, obtidas e criadas de acordo com a experiência de mercado do gestor da empresa, juntamente com dados externos, ou seja, dados diversos que influenciam na venda do produto, mas que antes não eram levados em conta, pois não se sabia como fazer o seu uso, o que foi sanado com a criação do sistema baseado em conhecimento. Todas as etapas do ciclo de criação de inteligência 
estão incluídas no sistema, uma vez que ele engloba tanto dados internos quanto externos, para posterior análise através do conjunto de regras criadas. A disseminação ainda não será feita de momento, pois para que isso ocorra é preciso que haja uma mudança de cultura organizacional, ou seja, é preciso que todas as pessoas se envolvam, sendo que este trabalho foca apenas a informação para ser disponibilizada ao gestor. Com a informação disponível, o gestor a avalia e a utiliza no processo decisório, fazendo um planejamento de uma próxima ação estratégica e uma nova coleta de dados.

A partir disso, pode-se relacionar sistemas baseados em conhecimento com inteligência competitiva e gestão do conhecimento, já que um é complemento do outro. Inteligência competitiva fornece toda base teórica de como deve ser feita a coleta, tratamento e disseminação de dados. A gestão do conhecimento traz conceitos de como administrar e gerenciar o conhecimento, uma vez que, ao longo dos anos, o ser humano vai adquirindo conhecimentos, e um indivíduo é diferente do outro. Assim, o desenvolvimento de tecnologias que privilegiam o conhecimento começa a aparecer cada vez de forma mais acentuada. Estamos entrando na chamada era do conhecimento, e os sistemas baseados em conhecimento aparecem para transformar dados coletados, e experiências específicas de cada indivíduo, em informação, que depois serão importantes para um processo decisório.

Pretende-se, em trabalhos futuros, criar indicadores de desempenho dentro da empresa, para que possam ser avaliadas as ações estratégicas e tomadas de decisão. Esses indicadores não foram possíveis criar nesta pesquisa, pois é necessário mais tempo de uso do sistema, a fim de que se tenham dados ou resultados históricos para que sejam comparados com dados atuais. Pretende-se também, através desta pesquisa, aplicar os sistemas inteligentes em outros setores da empresa, como produção, por exemplo, programando e reprogramando itens a serem produzidos, gerando assim sempre informações atualizadas e que correspondam ao ambiente e situação atual da empresa, seja ela de qual ramo for. O uso contínuo do sistema baseado em conhecimento é importante para que se consiga criar um histórico de decisões e através disso comparar decisões anteriores com as atuais, já tomadas com ajuda do sistema desenvolvido, analisando então todas as contribuições para a empresa. 
As principais contribuições desta pesquisa foram evidenciar a importância das informações em todo e qualquer processo de tomada de decisão, mostrando qual a relação dos itens pesquisados, ou seja, Inteligência Competitiva, Gestão do Conhecimento e Sistemas Baseados em Conhecimento, que é uma subárea da Inteligência Artificial.

\section{REFERÊNCIAS}

BEAL, Adriana. Gestão estratégica da informação: como transformar a informação e a tecnologia da informação em fatores de crescimento e de alto desempenho nas organizações. São Paulo: Atlas, 2004.

BOSE, R. Competitive intelligence process and tools for intelligence analysis. Industrial Management \& Data Systems, v. 108, n. 4, p. 510-28, 2008.

CERVO, A. L..; BERVIAN, P. A. Metodologia científica. 5. ed. São Paulo: Prentice Hall, 2002.

DIEHL, Astor A., TATIM, Denise C. Pesquisa em ciências sociais aplicadas: métodos e técnicas. São Paulo:Pearson, 2004.

FIDEL, Raya. The case study method: a case study. In: GLAZIER, Jack D. \& POWELL, Ronald R. Qualitative research in information management.

Englewood, CO: Libraries Unlimited, p.37-50, 1992.

GAITHER, Norman; FRAZIER, Greg. Administração da produção e operações. São Paulo: Pioneira Thomsom Learning, 2001.

KAPLAN, R. S.; NORTON, D. P. A estratégia em ação: balanced scorecard. 22. ed. São Paulo: Campus, 1997.

$\mathrm{KOH}, \mathrm{H}$;; HA, S.; KIM, T.; LEE, S.; A method of accumulation and adaptation of design knowledge. The International Journal of Advanced Manufacturing Technology, p. 943-949, 2005

LIA, Laboratório de Inteligência Artificial da Universidade Federal do Ceará, 1999.

NONAKA, Ikujiro; TAKEUSCHI, Hirotaka. Criação de conhecimento na empresa: como as empresar japonesas geram a dinâmica da inovação. 16. ed. Rio de Janeiro: Campus, 1997.

PELSMACKER, P.D., MULLER, M.L., CUYVERS, L. and JEGERS, M. Competitive intelligence practices of south african and belgian exporters. Marketing Intelligence \& Planning, v. 23, n. 6, p. 606-20, 2005. 
PORTER, MICHAEL E. Competição: estratégias competitivas essenciais. 4.edi. São Paulo: Campus, 2000.

PRUSAK, L.; MCGEE, J. V. Gerenciamento estratégico da informação: aumente competitividade e eficiência de sua empresa usando informação como ferramenta estratégica. 11. ed. Rio de Janeiro: Campus, 1994.

QUEL, Luiz F. Gestão de conhecimentos: os desafios e a complexidade nas organizações. São Paulo: Saraiva, 2006.

REZENDE, Solange O. Sistemas Inteligentes: fundamentos e aplicações. 1. ed. São Paulo: Manole, 2003.

RICHARDSON, Roberto J., Pesquisa social: métodos e técnicas. 3 ed. São Paulo: Atlas, 1999.

ROBBINS, Stephen P.Administração: mudanças e perspectivas. São Paulo: Saraiva, 2000.

RUDIO, Franz V. Introdução ao projeto de pesquisa científica. 21. ed. Rio de Janeiro: Vozes, 1997.

RUSSEL, Stuart; NORVIG, Peter. Inteligência artificial. Rio de Janeiro: Campus, 2004.

SANTOS, Sergio L.; LAURINDO, Fernando J. B. Tecnologia da informação e produtividade: identificação de fatores de suporte ao aumento da produtividade. In: ENCONTRO NACIONAL DE ENGENHARIA DE PRODUÇÃO - ENEGEP,24, 2004. Anais... Florianópolis - Santa Catarina, 2004.

SENAI (SERVIÇO NACIONAL DE APRENDIZAGEM INDUSTRIAL). Uma questão de inteligência competitiva. Disponível em: <www.senai.br/sb43/art-questao.htm>. Acesso em: 07 maio 2009

STAREC, C.; GOMES, E.; BEZERRA, J. Gestão estratégica da informação e inteligência competitiva. São Paulo: Saraiva, 2005.

TEO, T.S.H. and CHOO, W.Y.; Assessing the impact of using the internet for competitive intelligence. Information \& Management, v. 39, n.1,p. 67-83, 2001.

URAIKUL, Varanon; CHAN, Christine W. TONTIWACHWUTHIKUL, Paitoon. Artificial intelligence for monitoring and supervisory control of process systems. Engineering Applications of Artificial Intelligence, v. 20, p. 115-131, 2007.

VARGAS, Ricardo V. Manual prático do plano de projeto: utilizando o PMBOK Guide - aprenda a construir um plano de projeto passo a passo através de exemplos 3. ed. 2007. 
VAUGHAN, Liwen; YOU, Justin. Content assisted web co-link analysis for competitive intelligence. Journal Scientometrics, Canadá, v. 77, n.3, p. 433-444, 2008.

WANG, Wei-Tsong. Knowledge management adoption in times of crisis. Industrial Management and Data Systems, v 109, n 4, p 445-462, April 24, 2009.

WERMUTH, Sílvia L. P.; FROZZA, Rejane. PAZOS, Ruben E. P. Sistema de apoio a decisão na indústria para melhorias no tempo de setup em produção. ENCONTRO NACIONAL DE ENGENHARIA DE PRODUÇÃO - ENEGEP, 27, 2007. Anais...Foz do Iguaçu, PR, 2007.

WHITBY, Blay. Inteligência artificial: um guia para iniciantes. São Paulo: Madras, 2004.

WU, Ing-Long, Lin, Han-Chang. A strategy-based process for implementing knowledge management: an integrative view and empirical study. Journal of The American Society for Information Science and Technology, v. 60, n.4, p.789802, 2009

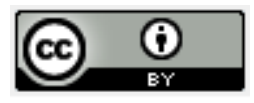

Artigo recebido em 03/08/2010 e aceito para publicação em 18/09/2011. 